Check for updates

Cite this: J. Anal. At. Spectrom., 2017, 32,1885

Received 14th June 2017 Accepted 10th July 2017

DOI: $10.1039 / \mathrm{c7ja00213k}$ rsc.li/jaas

\section{Spectroscopic diagnostics of axially viewed inductively coupled plasma and microwave induced plasma coupled to photochemical vapor generation with pneumatic nebulization inside a programmable temperature spray chamber}

\begin{abstract}
Jacek Giersz, (DD * Magdalena Bartosiak and Krzysztof Jankowski
Both argon inductively coupled plasma (ICP) and argon microwave induced plasma (MIP) coupled to photochemical vapor generation (PCVG) and pneumatic nebulization (PN) inside a programmable temperature cyclonic spray chamber (PTSC) have been widely characterized via optical emission spectrometry. Plasma diagnostics revealed an interesting relationship between fundamental plasma parameters and PTSC temperature in the examined range of $0-60{ }^{\circ} \mathrm{C}$ which was different for the two plasmas examined. For ICP, all measured parameters including rotational temperature $\left(T_{\text {rot }}\right)$, excitation temperature $\left(T_{\text {exc }}\right)$, ionization temperature $\left(T_{\text {ion }}\right)$ and electron number density $\left(n_{\mathrm{e}}\right)$ consequently increased (3-22\%) with increasing PTSC temperature. In turn, for MIP only $T_{\text {rot }}$ and $T_{\text {exc }}$ for Fe showed a similar trend while the other examined parameters slightly decreased (about 15\% for $n_{\mathrm{e}}$ and $T_{\text {exc }}$ for $\mathrm{Ar}$ with increasing PTSC temperature). As a result, ICP robustness increased with increasing PTSC temperature while MIP robustness decreased. Three factors influencing changes of plasma parameters were selected and considered including water transport efficiency, carbon-related matrix effect and analyte volatility. The observed trends are consistent with analytical data obtained previously and are supported by additional investigation of the sample transport efficiency of the sampling system. Thus, partial sample evaporation at elevated PTSC temperature is finally confirmed, although saturation of the nebulizer gas with water vapor is not achieved when it exits the PTSC. Enhancements of analyte emission intensity related to PTSC heating are due to the improved plasma robustness rather than higher sample transport efficiency.
\end{abstract}

\section{Introduction}

Inductively coupled plasma (ICP-OES) and microwave induced plasma optical emission spectrometry (MIP-OES) are commonly used for trace elements determination in aqueous solutions. In these two spectroscopic techniques, pneumatic nebulization (PN) is preferentially used as a liquid sample introduction technique. In spite of having a lot of advantages, PN suffers from low sample transport efficiency to the plasma (1-3\%) resulting in relatively high limits of detection (LODs) by ICPOES. ${ }^{1-3}$ In order to improve the analytical performance, vaporization of a sample aerosol in heated spray chambers without subsequent removal of water has been proposed for some analytical applications. Several heated spray chamber systems have been investigated. Peredes et $a .^{4}{ }^{4}$ described the effect of heating of a torch integrated sample introduction system (TISIS) on analytical figures of merit by ICP-OES. They showed

Warsaw University of Technology, Faculty of Chemistry, Noakowskiego Street 3, Warszawa,PL-00664,Poland.E-mail:jgiersz@ch.pw.edu.pl that when operating at a low sample flow rate, the rise of the spray chamber wall temperature up to $105^{\circ} \mathrm{C}$ provides 2 to 12 fold enhancement of sensitivity of ICP-OES measurements. Grotti et al..$^{5}$ described the effects of aerosol generation and desolvation processes on the analytical performance of ICP-OES combined with a pneumatic or an ultrasonic nebulizer equipped with a heated spray chamber operating at $145^{\circ} \mathrm{C}$. Schrön and Müller ${ }^{6}$ explored a similar system based on a heated spray chamber coupled with ICP-OES for multielement analysis of environmental and geological samples. Further, in order to increase or decrease the sample introduction efficiency, a programmable temperature spray chamber (PTSC) coupled with PN can be used as one of the promising solutions. PTSCs have been used in several ICP-OES and MIP-OES approaches which improved sample transport efficiency and lowered the LODs for some elements compared with a conventional nebulization system. Various commercial PTSC devices have been designed to reduce interferences and matrix effects in ICP spectrometry. ${ }^{7}$ Moreover, better performance, signal stability and limits of detection (LODs) have been obtained by applying 
this sample introduction system because of the ability to precisely control the amount of sample aerosol introduced to the plasma. The use of PTSC operating at low temperatures up to $10{ }^{\circ} \mathrm{C}$ coupled to ICP mass spectrometry was successful in analytical methodologies for the determination of trace elements mainly in petrochemical and food industry. ${ }^{7}$ Jankowski et al. examined PTSC influence on chemical vapor generation (CVG) and photochemical vapor generation (PCVG) of iodine in a temperature range from $5{ }^{\circ} \mathrm{C}$ to $60{ }^{\circ} \mathrm{C} .{ }^{8}$ They observed that setting of the spray chamber temperature up to $50{ }^{\circ} \mathrm{C}$ provided improved sample transport efficiency due to partial aerosol vaporization, thus leading to the increase of sensitivity and stability of iodine determination by CVG-ICPOES. Other applications of PTSC for determination of $\mathrm{Hg}, \mathrm{Se}$, As and Sb in ICP-OES and MIP-OES with direct CVG have been described by Giersz and Jankowski, ${ }^{9}$ and recently by Giersz et $a l .{ }^{10}$ for simultaneous determination of $\mathrm{Hg}, \mathrm{Fe}, \mathrm{Cu}$ and $\mathrm{Mn}$ by PCVG-ICP-OES. The use of PTSC improved the analytical performance for all examined plasma spectrometric techniques. Interestingly, in the case of ICP-OES the use of elevated PTSC temperature seems to be beneficial for improving the sensitivity and LODs, but for MIP-OES definitely cooling of sample aerosol has offered better analytical results so far.

It was found that water vapor loading has a high impact on analyte signals in both ICP-OES and MIP-OES. Zhu and Browner ${ }^{11}$ reported the influence of water vapor loading as a function of Scott-type spray chamber temperature on ICP-OES spectral characteristics. In addition, they observed variations of Ti(II) excitation temperature ( $\left.T_{\text {exc }}\right)$ and electron number density $\left(n_{\mathrm{e}}\right)$ and found that these parameters were practically independent of sample loading for the chamber wall temperature varying between 0 and $40{ }^{\circ} \mathrm{C}$. Giersz and Jankowski studied the relationship between the temperature of the sample introduced to the plasma and plasma OES characteristics for Ar MIP, He MIP and Ar ICP. ${ }^{9}$ They reported that the intensity ratio for the line pair $\mathrm{Mg}$ (II) 280.270/Mg(I) 285.213 for Ar-ICP increases from 12 to 13 with increasing PTSC temperature. Long and Browner ${ }^{12}$ investigated the effect of water loading on the plasma properties including the background level, $n_{\mathrm{e}}$ and ionization temperature $\left(T_{\text {ion }}\right)$ for Ar ICP. They observed a slight increase of both $T_{\text {ion }}$ and $n_{\mathrm{e}}$ with increasing water vapor loading in the range of 5-27 mg $\mathrm{L}^{-1}$, and a significant drop of $T_{\text {ion }}$ from $7960 \mathrm{~K}$ to $7020 \mathrm{~K}$ for water vapor plus aerosol loadings exceeding $27 \mathrm{mg} \mathrm{L}^{-1}$. In turn, Pohl and Broekaert ${ }^{\mathbf{1 3}}$ observed that $T_{\text {exc }}$ values measured for Ar, $\mathrm{Au}, \mathrm{Bi}$ and Fe atomic species in Ar ICP increased after replacing pneumatic nebulization by a simultaneous hydride generation and pneumatic nebulization system providing combined aerosol and vapor loading. Moreover, sample introduction in the vapor form alone led to further increase of $T_{\text {exc }}$ for Ar, Au and Bi. Similar trends were observed for Ar MIP. ${ }^{14}$

In a number of papers, carbon-related matrix effect on plasma properties has been studied ${ }^{\mathbf{1 5}, 16}$ including the effect of low-molecular-weight organic acids. ${ }^{\mathbf{1 7 - 2 0}}$ Also, the ethanol concentration influence on plasma characteristics for Ar-MIPOES coupled with CVG and a gas-liquid separator has been described by Włodarczyk and Żyrnicki. ${ }^{21}$ They found that with ethanol concentration in the sample from 10 to $90 \% T_{\text {rot }}$

increased from 2970 to $3820 \mathrm{~K}$ while $T_{\text {exc }}$ of $\mathrm{Ar}, \mathrm{H}$ and $\mathrm{Sb}$ lowered in the ranges 5670-4800, 6190-3950 and 10 500-7390 K, respectively. Simultaneously, the decrease of $n_{\mathrm{e}}$ value from 2.5 $\times 10^{15}$ to $0.57 \times 10^{15} \mathrm{~cm}^{-3}$ was observed.

The PTSC influence on multiple plasma characteristics in both Ar-MIP and ICP-OES in the examined range of $0-60{ }^{\circ} \mathrm{C}$ during PCVG has not been studied yet. Recently, only the $\mathrm{OH}$ rotational temperature for both Ar-ICP and Ar-MIP coupled with PN-PTSC has been measured. ${ }^{9}$ The aim of this study was careful investigation of the PCVG-PN-PTSC sampling system and examination of its influence on ICP and MIP characteristics in order to determine the optimal PTSC temperature for both PCVG-PN-PTSC-ICP-OES and PCVG-PN-PTSC-MIP-OES techniques.

\section{Experimental}

\subsection{Instrumentation}

In this study two plasma sources have been examined, an ICP source as an integral part of Integra XL (GBC, Australia) OES spectrometer and a stand-alone MIP source based on a TE101 cavity equipped with an MIP-2 (ERTEC, Poland), described elsewhere. ${ }^{22}$ Both sources worked under fixed and optimized operating conditions listed in Table 1.

The optimization of both sources was very brief as the aim of the study was to investigate commonly used plasma sources operating close to standard conditions. For both sources it was performed in order to obtain robust, stable plasmas, not affected by frequent changes of conditions and increased solvent load at elevated PTSC temperature. Mainly plasma supply power (for ICP and MIP) and sample flow (for MIP only) rate were the optimized parameters. The sampling setup (previously described in ref. 10), consisted of a lab-made photochemical reactor, a concentric nebulizer AR40-07 (Glass Expansion, Australia) working at $2 \mathrm{~mL} \mathrm{~min}^{-1}$ sample flow rate and a standard cyclonic spray chamber V2 equipped with an Isomist Module (Glass Expansion, Australia) for controlling and monitoring spray chamber temperature between $-10{ }^{\circ} \mathrm{C}$ and $+60{ }^{\circ} \mathrm{C}$ with an accuracy of $\pm 0.1^{\circ} \mathrm{C}$. The PCVG reactor consisted of a $3 \mathrm{~mm}$ i.d. wide and $68 \mathrm{~cm}$ long quartz tube $\left(4.6 \mathrm{~cm}^{3}\right.$ volume $)$

Table 1 ICP and MIP sources operating conditions

ICP

Plasma power supply

Plasma gas flow rate

Auxiliary gas flow rate

Carrier gas flow rate

$1250 \mathrm{~W}$

$14 \mathrm{~L} \mathrm{~min}^{-1}$

$1 \mathrm{~L} \mathrm{~min}^{-1}$

$450 \mathrm{~mL} \mathrm{~min}^{-1}$

MIP

Plasma power supply

Plasma/carrier gas flow

rate

Quartz tube inner

diameter
$240 \mathrm{~W}$ $450 \mathrm{~mL} \mathrm{~min}^{-1}$

$4 \mathrm{~mm}$ 
coiled around a low-pressure $11 \mathrm{~W}$, UV-C mercury lamp (Philips). For investigation of the solvent transport efficiency, a filter housing with a glass filter $(47 \mathrm{~mm}$ diameter, Pall-Gelman, Mexico) and a lab-made water adsorber filled with molecular sieves type 13X were used (Fig. 1). A Minipuls 3 peristaltic pump (Gilson, Switzerland) was used for delivering the sample to the experimental setup.

For plasma diagnostics measurements, the emission from both examined plasmas was axially viewed and directed via an optical fiber P600-2-SR with a collimating quartz lens to four miniature optic CCD spectrometers: AvaSpec-2048 XL, AvaSpec3648-UF, AvaSpec-3648-UE (Avantes Netherlands), and USB4000 (Ocean Optics USA) covering spectral ranges of 190-355, 270$330,330-430$ and $430-630 \mathrm{~nm}$, respectively, and a spectral resolution of $0.08,0.015,0.03$ and $0.06 \mathrm{~nm}$, respectively.

\subsection{Reagents and standards}

High grade analytical reagents obtained from POCh (Poland) were employed for the preparation of all solutions. A standard stock solution of magnesium $\left(1000 \mathrm{mg} \mathrm{L}^{-1}\right)$ was prepared from magnesium sulfate in $2 \% \%_{\mathrm{v} / \mathrm{v}} \mathrm{HNO}_{3}$, standard stock solution of iron (1000 $\mathrm{mg} \mathrm{L}^{-1}$ ) from iron(III) oxide in $2 \% \mathrm{v} / \mathrm{v} \mathrm{HNO}_{3}$, and standard stock solution of nickel (1000 $\mathrm{mg} \mathrm{L}^{-1}$ ) from nickel(II) chloride in $2 \% \%_{\mathrm{v} / \mathrm{v}} \mathrm{HNO}_{3}$. Working single- and multi-element standard solutions were freshly prepared daily by serial dilution of the stock solutions with distilled water, and subsequent addition of an appropriate volume of $99.5 \%_{\mathrm{v} / \mathrm{v}}$ formic acid (ACS reagent, Sigma Aldrich, Germany). Acid-base titration of formic acid was carried out with $0.3260 \mathrm{~mol} \mathrm{~L}^{-1}$ standard sodium hydroxide solution in the presence of phenolphthalein.

\subsection{PCVG procedure}

For both ICP-OES and MIP-OES measurements the analyzed solutions containing $10 \%{ }_{\mathrm{v} / \mathrm{v}}$ formic acid were pumped with the peristaltic pump passing through an air cooled quartz reactor operating at $40{ }^{\circ} \mathrm{C}$ while being subjected to UV radiation. Next, the resulting sample solutions were on-line nebulized by the

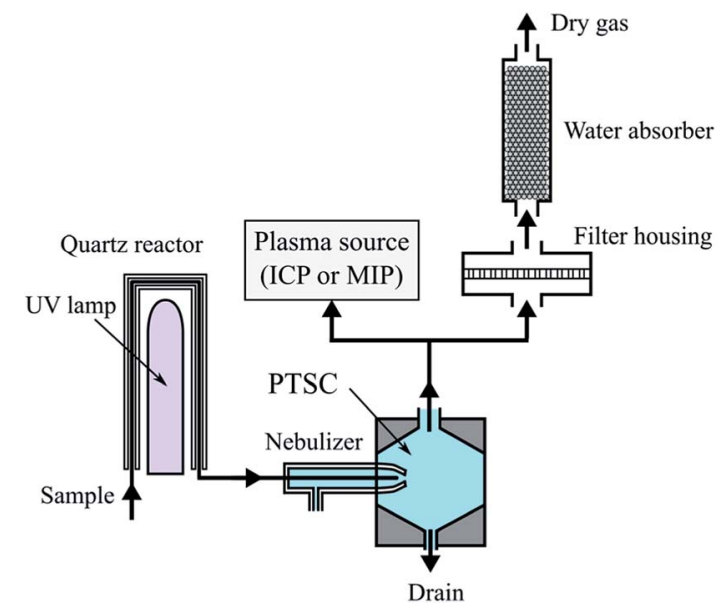

Fig. 1 Schematic diagram of the experimental setup for solvent transport efficiency measurements and spectroscopic diagnostics. conical nebulizer connected to the PTSC and then directed to the plasma. Teflon tubing of $1 \mathrm{~mm}$ diameter was used to transfer samples between the pump, PCVG reactor and nebulizer. In the case of ICP-OES measurements the sample flow rate was $1.6 \mathrm{~mL} \mathrm{~min}^{-1}$ and $0.4 \mathrm{~mL} \mathrm{~min}^{-1}$ for MIP-OES measurements. After PCVG-MIP-OES experiments with solutions containing $\mathrm{Ni}$, a cleaning procedure was applied in order to minimize the memory effect. The sampling system was flushed with a solution containing $3 \mathrm{~mol} \mathrm{~L}^{-1} \mathrm{HNO}_{3}$ and $0.5 \mathrm{~mol} \mathrm{~L}^{-1}$ $\mathrm{H}_{2} \mathrm{O}_{2}$ for about 2 minutes.

\subsection{Plasma diagnostics measurements}

Useful spectra of various thermometric species including $\mathrm{Ar}, \mathrm{Ni}$, $\mathrm{Fe}, \mathrm{Mg}, \mathrm{H}, \mathrm{OH}$ and $\mathrm{N}_{2}$ particles were registered in the spectral range between 230 and $500 \mathrm{~nm}$. The combined spectrum showing all bands and lines used for diagnostic parameter calculations is shown in Fig. 2. The portions of spectrum come from several different detectors and are not normalized to each other with respect to intensity. Despite numerous Ni lines observed in both ICP and MIP spectra, only few were free from spectral interferences and could be used for determining $\mathrm{Ni}$ excitation temperature.

Diagnostic parameters characterize fundamental plasma features including vaporization efficiency of sample aerosol droplets, the energy of excited atoms or plasma gas temperature. The electron number density was calculated from the Stark broadening of the $\mathrm{H}_{\beta}$ line at $486.16 \mathrm{~nm}$ based on the full width of half maximum (FWHM). Useful equations are given below:

$$
\begin{gathered}
n_{\mathrm{e}}=C\left(n_{\mathrm{e}}, T_{\mathrm{e}}\right) d^{1.5} \\
b=\left(\frac{d^{2}}{4}+g_{\mathrm{T}}\right)^{0.5}+\frac{d}{2} \\
g_{\mathrm{T}}=\left(g_{\mathrm{D}}^{2}+g_{\mathrm{I}}^{2}\right)^{0.5} \\
g_{\mathrm{D}}=7.1 \times 10^{-7} \lambda\left(\frac{T_{\mathrm{g}}}{M}\right)^{0.5}
\end{gathered}
$$

where $C\left(n_{\mathrm{e}}, T_{\mathrm{e}}\right)$ is a coefficient dependent on electron number density and electron temperature, $b$ is the total line broadening, $d$ is Stark broadening, and $g_{\mathrm{T}}$ is the sum of Doppler broadening $\left(g_{\mathrm{D}}\right)$ and instrumental broadening $\left(g_{\mathrm{I}}\right)$. $\lambda$ signifies $\mathrm{H}_{\beta}$ wavelength, $T_{\mathrm{g}}$ is the gas temperature (rotational temperature of $\mathrm{OH}$

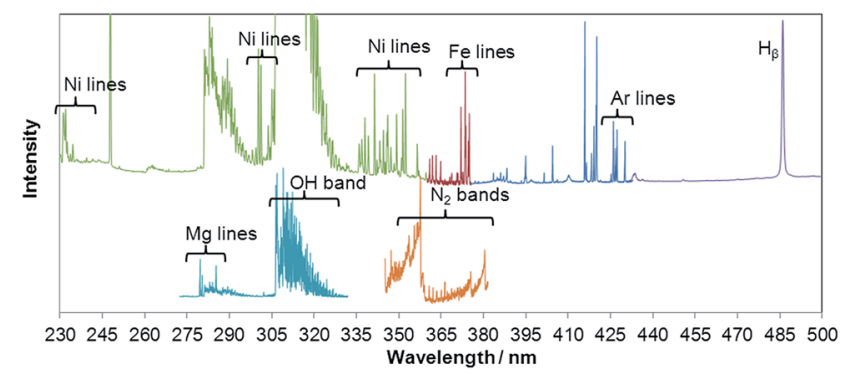

Fig. 2 Presentation of a combined spectrum showing all bands and lines used for plasma diagnostics. 
radicals can be used instead) and $M$ is hydrogen atomic mass. The $C\left(n_{\mathrm{e}}, T_{\mathrm{e}}\right)$ values were taken from ref. 23 and equaled $1.16 \times$ $10^{14}$ and $3.68 \times 10^{14} \mathrm{~cm}^{-3}$ for MIP and ICP, respectively. For low power MIPs $(100-250 \mathrm{~W}), g_{\mathrm{D}}$ may be omitted since $T_{\mathrm{g}}$ is usually much lower than that for ICP. Moreover, the low resolution of the applied spectrometer operating in the range $430-630 \mathrm{~nm}$ implied a relatively high instrumental broadening value (about $0.15 \mathrm{~nm}$ ), thus $g_{\mathrm{D}}$ calculation had to be considered for ICP only. The uncertainty of $n_{\mathrm{e}}$ calculation was estimated to be $10 \%$. Ionization temperature $\left(T_{\text {ion }}\right)$ was calculated by applying a combination of Saha and Boltzmann equations, using the ion to atom emission intensity ratio for magnesium. As $T_{\text {ion }}$ is a function of $n_{\mathrm{e}}$, its uncertainty was also estimated to be about $10 \%$. This method of $T_{\text {ion }}$ calculation requires previous $n_{\mathrm{e}}$ determination. The respective Saha equation is given below:

$$
\frac{I_{\mathrm{qp}}^{+}}{I_{\mathrm{qp}}}=\frac{4.83 \times 10^{15}}{n_{\mathrm{e}}} \frac{g_{\mathrm{q}}^{+} A_{\mathrm{qp}}^{+}}{\lambda_{\mathrm{qp}}^{+}} \frac{\lambda_{\mathrm{qp}}}{g_{\mathrm{q}} A_{\mathrm{qp}}}\left[T_{\mathrm{ion}}\right]^{\frac{3}{2}} \exp \left(-\frac{E_{\text {ion }}+E_{\mathrm{q}}^{+}-E_{\mathrm{q}}}{k T_{\text {ion }}}\right)
$$

where $E_{\mathrm{q}}$ is the energy of a particular transition, $E_{\text {ion }}$ is the ionization energy, $\lambda$ is the respective magnesium wavelength, $I$ is the intensity, $A$ is the transition probability, $g$ is the statistical weight, $T_{\text {ion }}$ is the ionization temperature, and $k$ is the Boltzmann constant. Magnesium is often chosen for the ionization temperature calculation, as it emits both strong ionic and atomic lines in a narrow spectral range (only $5 \mathrm{~nm}$ distance between ionic and atomic lines). This allows for calculation without specific line intensity calibration since detector sensitivity in such a spectral range may be considered constant. Also, the ion to atom emission intensity ratio of magnesium itself is sometimes used to define plasma robustness. ${ }^{8}$ The calculation of the ionization temperature of magnesium was based on spectroscopic data listed in Table 2.

The other plasma temperatures including $T_{\text {exc }}, T_{\text {rot }}$, and $T_{\text {vib }}$ can be determined by the Boltzmann-plot method. Correlation equations for each temperature type are given below, respectively:

$$
\begin{gathered}
\ln \frac{I_{\mathrm{ki}} \lambda_{\mathrm{ki}}}{S(\lambda) g_{\mathrm{k}} A_{\mathrm{ki}}}=\frac{-E_{\mathrm{k}}}{k T_{\mathrm{exc}}}+\text { const } \\
\ln \frac{\lambda^{4} I_{J^{\prime} J^{\prime \prime}}}{S_{J^{\prime} J^{\prime \prime}} A_{\lambda}}=\frac{-h c F^{\prime}(J)}{k T_{\mathrm{rot}}}+\mathrm{const} \\
\ln \frac{I\left(\nu^{\prime} \rightarrow \nu^{\prime \prime}\right) \lambda^{3}}{S(\lambda) q\left(\nu^{\prime} \rightarrow \nu^{\prime \prime}\right)}=\frac{-E_{\nu^{\prime}}}{k T_{\mathrm{vib}}}+\mathrm{const}
\end{gathered}
$$

$E_{\mathrm{k}}, h c F^{\prime}\left(J^{\prime}\right)$, and $E_{\nu}$ signify energies of a particular level change (energy of transition), $S_{J^{\prime} J^{\prime \prime}}$ is the Honl-London factor, $q$ is the Frank-Condon factor (transition probability), $S(\lambda)$ is the detector sensitivity, $\nu$ is the vibrational quantum number, and $J$ is the rotational quantum number. Rotational temperature has been measured using the $\mathrm{OH}\left(\mathrm{A}^{2} \Sigma \rightarrow \mathrm{X}^{2} \Pi\right)$ transition. The vibrational temperature of $\mathrm{N}_{2}$ has been measured using the second positive system $\left(\mathrm{C}^{3} \Pi_{\mathrm{u}} \rightarrow \mathrm{B}^{3} \Pi_{\mathrm{g}}\right)$ of nitrogen molecule. $T_{\text {vib }}$ measurements were carried out for MIP only, since no $\mathrm{N}_{2}$

\begin{tabular}{|c|c|c|c|}
\hline Object & Wavelength/nm & Energy or $h c F / \mathrm{eV}$ & gA or FCF \\
\hline \multirow[t]{5}{*}{$T_{\text {exc }}(\mathrm{Ar})$} & 425.118 & 14.473 & 0.0396 \\
\hline & 425.936 & 14.748 & 0.45 \\
\hline & 426.629 & 14.539 & 0.18 \\
\hline & 427.217 & 14.535 & 0.27 \\
\hline & 430.010 & 14.516 & 0.21 \\
\hline \multirow[t]{9}{*}{$T_{\text {exc }}(\mathrm{Fe})$} & 367.992 & 3.371 & 0.1242 \\
\hline & 370.557 & 3.399 & 0.2296 \\
\hline & 371.994 & 3.334 & 1.793 \\
\hline & 372.256 & 3.419 & 0.2525 \\
\hline & 373.487 & 4.180 & 8.536 \\
\hline & 373.713 & 3.371 & 1.26 \\
\hline & 374.949 & 4.223 & 6.129 \\
\hline & 375.824 & 4.259 & 4.277 \\
\hline & 376.379 & 4.286 & 2.615 \\
\hline \multirow{5}{*}{$T_{\text {exc }}(\mathrm{Ni})$} & 301.09 & 4.541 & 15 \\
\hline & 337.97 & 4.092 & 6.1 \\
\hline & 341.34 & 3.658 & 5.7 \\
\hline & 344.53 & 3.708 & 3.8 \\
\hline & 352.45 & 3.545 & 4.6 \\
\hline \multirow{9}{*}{$T_{\text {rot }}(\mathrm{OH})$} & 307.8 & 4.029 & 10.0 \\
\hline & 308.0 & 4.038 & 17.0 \\
\hline & 308.3 & 4.067 & 33.7 \\
\hline & 308.5 & 4.088 & 42.2 \\
\hline & 308.7 & 4.113 & 50.6 \\
\hline & 311.0 & 4.399 & 100.6 \\
\hline & 311.5 & 4.456 & 108.8 \\
\hline & 312.0 & 4.516 & 125.2 \\
\hline & 313.7 & 4.716 & 149.6 \\
\hline \multirow[t]{5}{*}{$T_{\mathrm{vib}}\left(\mathrm{N}_{2}\right)$} & 353.67 & 0.37 & 0.2033 \\
\hline & 357.69 & 0.13 & 0.3291 \\
\hline & 371.05 & 0.61 & 0.1605 \\
\hline & 375.56 & 0.37 & 0.1990 \\
\hline & 380.49 & 0.13 & 0.1462 \\
\hline \multirow[t]{2}{*}{$T_{\text {ion }}(\mathrm{Mg})$} & 279.55 & 4.434 & 10.40 \\
\hline & 285.21 & 4.346 & 14.73 \\
\hline
\end{tabular}

Table 2 Numerical values of energies and spectral constants for all lines or bandheads used for temperature calculation. Data have been acquired from ref. 26-29

emission was observed for ICP. Also, for ICP measurements, the intensities of some lines from the $\mathrm{OH}$ band were not sufficiently high to be used for reliable temperature calculation by the Boltzmann plot method. For better comparison between the two examined plasmas, in both cases, a simplified method of $\mathrm{OH}$ rotational temperature determination was used, as described by Izarra. ${ }^{24}$ Additionally, $T_{\text {rot }}$ determination by the Boltzmann plot method was applied for the MIP spectrum for comparison. In the method proposed by Izarra, intensities of the main $\mathrm{OH}$ band heads $R_{1}, R_{2}$ and $Q_{2}$ are used at $306.573 \mathrm{~nm}, 306.776 \mathrm{~nm}$ and $308.986 \mathrm{~nm}$, respectively, and the method is applicable even at low optical resolution of the experimental setup. $T_{\text {rot }}$ can be easily calculated from $R_{1} / Q_{2}$ or $R_{2} / Q_{2}$ intensity ratio. However, instrumental broadening $\Delta$ of the optical system used should be known. This parameter is defined as the full width of an atomic line at $1 / e$ of its height. For the spectrometer used (AvaSpec-2048 XL), $\Delta$ was measured using the mercury line at $296.728 \mathrm{~nm}$ taken from a low pressure mercury lamp and it was estimated to be $0.28 \mathrm{~nm}$. According to Izarra, ${ }^{24}$ the accuracy of $T_{\text {rot }}$ determination for ICP by this method is lower than that for 
MIP since for $T_{\text {rot }}$ above $4000 \mathrm{~K}$ the slopes of both function plots $R_{1} / Q_{2}=f\left(T_{\text {rot }}\right)$ and $R_{2} / Q_{2}=f\left(T_{\text {rot }}\right)$ decrease resulting in an increase of error in the temperature determination. For the other temperatures determined, the uncertainty was calculated based on the error estimated for the slope of the respective Boltzmann plot. ${ }^{25}$ All spectroscopic data are listed in Table 2. All diagnostic parameters were calculated as average values of three independent measurements.

\section{Results and discussion}

\subsection{Solvent transport efficiency of the PCVG-PN-PTSC system}

The solvent transport efficiency was determined by two independent procedures using the system consisting of an aerosol filter and a vapor adsorption unit, as shown in Fig. 1. In the first procedure, sample aerosol exiting the PTSC was separated from the combined aerosol and vapor mixture by using a glass filter. The amount of vapor was measured by weighting of the adsorption unit before and after the experiment. In the second experiment, the glass filter was removed and the total sample amount was trapped in the adsorption unit. Next, the sample aerosol transport efficiency was calculated by the difference between the total sample loading and the vapor loading. Two different sample matrices were investigated in this experiment including water and $10 \%_{\mathrm{v} / \mathrm{v}}$ formic acid solution. The determined solvent transport efficiencies as a function of PTSC temperature are shown in Fig. 3.

While water aerosol transport efficiency seems to be slightly dependent on PTSC temperature, water vapor transport efficiency increases by 4 -fold when heating PTSC from 0 to $60{ }^{\circ} \mathrm{C}$ (see Fig. 3A). The results obtained show a similar trend to those reported by Zhu and Browner ${ }^{11}$ where the effect of the Scott-type chamber operating in the $0-35{ }^{\circ} \mathrm{C}$ temperature range on water loading was investigated. However, in our study the increase is less pronounced than that determined in ref. 11 where 4 -fold increase of vapor loading was obtained even faster between 0 and $30^{\circ} \mathrm{C}$. This indicates that heat transfer between the PTSC wall and carrier gas is less effective than that in the Scott-type chamber. Moreover, one can conclude that Ar is not saturated with water vapor when leaving the PTSC. ${ }^{11}$
The results obtained for formic acid solution differ in some aspects. While vapor transport efficiency is very similar for the two solutions (about 3\%), both total solvent transport and aerosol transport efficiencies for formic acid solution are visibly higher compared to pure water nebulization. The boiling points of water and formic acids are comparable (for $\mathrm{HCOOH} 100-101$ $\left.{ }^{\circ} \mathrm{C}\right)$ so vaporization effects for these liquids are expected to be similar. However, Tormen et al. ${ }^{17}$ reported about 25\% increase of signals by PN-ICP-MS for a number of elements when about $10 \%_{\mathrm{v} / \mathrm{v}}$ of formic acid was present in the sample. They suspected that the addition of an organic acid caused decrease of surface tension of the sample solution, thus favoring the formation of a finer and more stable aerosol. Owing to these effects, sample aerosol was both generated and transferred to the plasma with better efficiency. This explains our observation that sample aerosol transport rate is 2 times higher when formic acid is present in the sample. Moreover, the ratio of aerosol transport efficiency is practically independent of the PTSC temperature in the whole temperature range examined. Consequently, the total sample loading is also significantly higher for formic acid solution compared to water.

It is well known that UV irradiation causes decomposition of formic acid into gaseous products. ${ }^{30}$ In order to evaluate the formic acid degradation rate under UV irradiation in our experimental setup, the $\mathrm{HCOOH}$ concentration has been determined in the collected drain by acid-base titration. No difference was observed for $\mathrm{HCOOH}$ concentration in solution before and after UV irradiation. It means that a very small amount of formic acid was decomposed during the photochemical process. Also, the temperature of PTSC did not affect $\mathrm{HCOOH}$ concentration in the collected drain for the whole temperature range.

\subsection{Plasma diagnostics of ICP and MIP coupled with the PCVG-PN-PTSC system}

For both ICP and MIP, plasma diagnostics have been performed under the fixed, optimized conditions given in Table 1 . The only varying parameter was the temperature of PTSC. All metals serving as thermometric species were introduced to the plasma
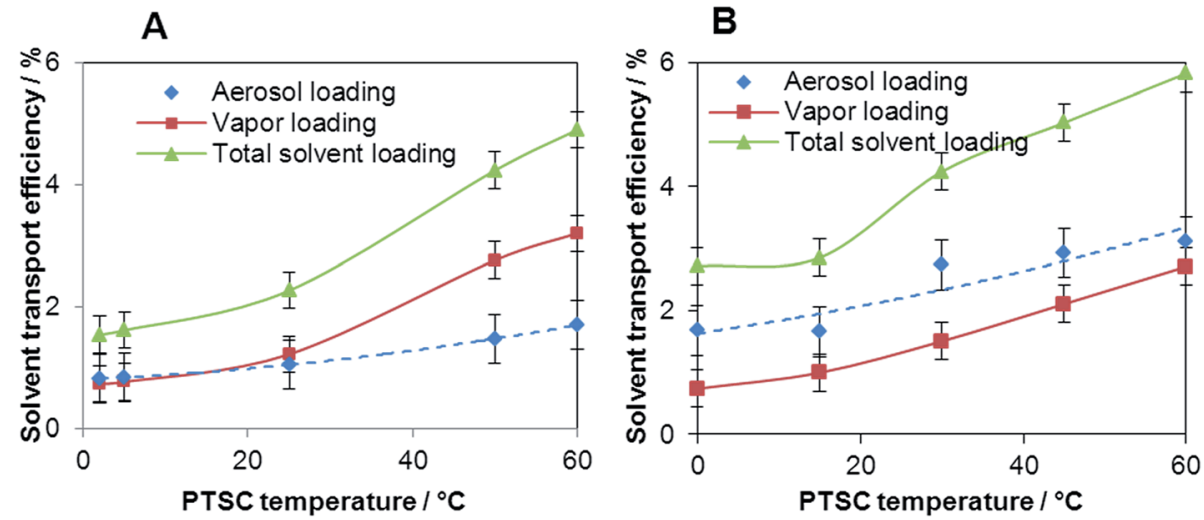

Fig. 3 Water vapor and aerosol loading variation versus PTSC temperature: (A) shows data obtained for water, and (B) for 10\% formic acid solution. 
separately via pneumatic nebulization. All Boltzmann plots used for temperature calculations exhibited fair linearity with correlation factors above 0.9. Electron number density values and temperatures of thermometric species measured at the lowest and the highest examined PTSC temperatures have been collected in Table 3 . In the case of the MIP-based system, the highest applicable PTSC temperature was $50{ }^{\circ} \mathrm{C}$, because further temperature increase led to plasma extinguishment.

As expected, Ar ICP is characterized by generally much higher temperatures than Ar MIP (see Table 3). This is a result of applying much higher plasma power. For ICP, the difference between $T_{\text {exc }}$ for Ar and that for Fe is about $600 \mathrm{~K}$, while for MIP it is $1500 \mathrm{~K}$, which indicates strong departure from thermal equilibrium for the examined Ar MIP. However, when operating at low PTSC temperature, both plasma sources are characterized by a typical sequence of temperatures of non-LTE plasma: $T_{\text {ion }}>T_{\text {exc }}>T_{\text {vib }}>T_{\text {rot }}$. The temperature values are comparable to those available in the literature..$^{12,17-20,31}$ Comparing pneumatic nebulization and hydride generation with simultaneous introduction of the sample aerosol into ICP, Pohl and Broekaert ${ }^{13}$ found that $T_{\text {exc }}$ for $\mathrm{Ar}, \mathrm{Au}, \mathrm{Bi}$ and $\mathrm{Fe}$ atoms varied in the range 6700-7000, 6400-6600, 2900-3000, and 6800-7400 K, respectively, being higher in the case of combined vapor plus aerosol sample loading.

In turn, when operating at an elevated PTSC temperature, for MIP $T_{\text {exc }}(\mathrm{Ar})$ is very close to $T_{\text {rot }}(\mathrm{OH})$ and it is lower than $T_{\mathrm{vib}}\left(\mathrm{N}_{2}\right)$ indicating that argon low-energy states are not in Saha equilibrium. ${ }^{32}$ By contrast, $T_{\text {exc }}(\mathrm{Ni})$ is only slightly lower than $T_{\text {ion }}(\mathrm{Mg})$. This can be explained by the formation of volatile nickel carbonyl by using the PCVG technique. Under the applied conditions, the efficiency of $\mathrm{Ni}(\mathrm{CO})_{4}$ generation was found to be about $20-30 \%,{ }^{33,34}$ and $\mathrm{Ni}(\mathrm{CO})_{4}$ easily decomposes in plasma to $\mathrm{Ni}^{0}$ and $\mathrm{CO}$ since its thermolysis begins at $180{ }^{\circ} \mathrm{C}$.

This conclusion is further confirmed by additional experiments on the determination of $T_{\text {exc }}(\mathrm{Ni})$ for both ICP and MIP combined with pneumatic nebulization. For MIP, when Ni standard solutions were introduced by $\mathrm{PN}, T_{\text {exc }}(\mathrm{Ni})$ reached $4450 \mathrm{~K}$ and $5600 \mathrm{~K}$ for water-based solution and that containing $10 \%_{\mathrm{v} / \mathrm{v}}$ of formic acid, respectively. It seems that the decomposition of formic acid in Ar MIP, forming $\mathrm{CO}$ and $\mathrm{H}_{2}$ leads to $T_{\text {exc }}$ increase of about $800 \mathrm{~K}$. However, additional UV radiation of the HCOOH-containing solution under PCVG conditions and formation of volatile $\mathrm{Ni}(\mathrm{CO})_{4}$ caused further elevation of $T_{\text {exc }}(\mathrm{Ni})$ to $6600 \mathrm{~K}$. A similar effect has been observed in the ICP-based system where $T_{\text {exc }}(\mathrm{Ni})$ value reached $3600 \mathrm{~K}$ for both waterbased and formic acid containing solution vs. 3900-4000 K after PCVG. This effect in MIP is even stronger ${ }^{21}$ probably due to the lower ionization degree of $\mathrm{Ni}$ in this plasma.

\subsection{Effect of heating of PTSC on plasma parameters}

The results of the systematic study of the effect of increasing PTSC temperature on different ICP and MIP plasma parameters derived from neutral and ionic species are shown in Fig. 4. Generally, a majority of the parameters vary slightly with increasing PTSC temperature under PCVG-PN-PTSC conditions. The most spectacular changes are observed for $n_{\mathrm{e}}$ and $T_{\text {rot }}$ (for both about $20 \%$ increase for ICP, and $17 \%$ decrease of $n_{\mathrm{e}}$ but $17 \%$ increase of $T_{\text {rot }}$ for MIP between the lowest and the highest PTSC temperature applied). Also, for $T_{\mathrm{vib}}\left(\mathrm{N}_{2}\right)$ significant change has been observed (28\% increase for MIP). For both MIP and ICP the most stable parameter was $T_{\text {ion }}(\mathrm{Mg})$ with respect to the measurement error estimated for this temperature, which was about $7 \%$.

For ICP, increasing the PTSC temperature led to increase of all calculated plasma temperatures and $n_{\mathrm{e}}$ which actually means that despite increased water loading ICP becomes more robust and dense. Long and Browner reported similar observations after increasing water vapor loading to ICP operating under robust conditions. ${ }^{12}$ According to Tang and Trassy $^{\mathbf{3 1}}$ water dissociation products $\left(\mathrm{OH}, \mathrm{H}, \mathrm{O}, \mathrm{H}^{+}, \mathrm{O}^{+}, \mathrm{OH}^{+}\right)$improve the energy transfer efficiency and emission rate of plasma species. As it was further confirmed in our previous studies by determining numerous analytes, the higher the PTSC temperature, the stronger the emission intensity of the analytes and the lower their LOD values. ${ }^{8,9}$ These results clearly state that ICP robustness rises with increasing PTSC temperature leading to increased signal intensity. Actually, the value of the $\mathrm{Mg}$ $280.270 \mathrm{~nm}$ to $\mathrm{Mg} 285.213 \mathrm{~nm}$ line intensity ratio increased from 7.7 at $0{ }^{\circ} \mathrm{C}$ to 8.5 at $60{ }^{\circ} \mathrm{C}$ of the PTSC temperature. Moreover, the $n_{\mathrm{e}}$ value increased by $20 \%$ due to increased water vapor loading, which is significantly higher compared with the change observed by Grotti et al. in their study while increasing water aerosol loading. ${ }^{35}$

MIP response on increasing PTSC temperature seems to be more significant than ICP. Both $T_{\text {exc }}(\mathrm{Fe})$ and $T_{\text {rot }}(\mathrm{OH})$ increase, however $T_{\text {exc }}(\mathrm{Ar}), T_{\text {exc }}(\mathrm{Ni})$, and $n_{\mathrm{e}}$ definitely decrease. Again, Grotti et al. ${ }^{35}$ observed similar $n_{\mathrm{e}}$ decrease with increasing water amount delivered to ICP under non-robust conditions $(800 \mathrm{~W})$. Since some measured temperatures become lower and others higher, stronger deviation from thermal equilibrium is expected for the MIP. The decrease of $T_{\text {exc }}(\mathrm{Ar})$ with simultaneous increase

Table 3 Diagnostic parameter values calculated for Ar-ICP and Ar-MIP combined with PCVG-PN-PTSC operating at a PTSC temperature of $0{ }^{\circ} \mathrm{C}$ and 50 or $60{ }^{\circ} \mathrm{C}^{a}$

\begin{tabular}{|c|c|c|c|c|c|c|c|}
\hline Plasma parameter, unit & $n_{\mathrm{e}}, 10^{-15} \mathrm{~cm}^{-3}$ & $T_{\text {exc }}(\mathrm{Ar}), \mathrm{K}$ & $T_{\text {exc }}(\mathrm{Fe}), \mathrm{K}$ & $T_{\text {exc }}(\mathrm{Ni}), \mathrm{K}$ & $T_{\text {rot }}(\mathrm{OH}), \mathrm{K}$ & $T_{\text {ion }}(\mathrm{Mg}), \mathrm{K}$ & $T_{\text {vib }}\left(\mathrm{N}_{2}\right), \mathrm{K}$ \\
\hline $\operatorname{MIP}\left(T_{\mathrm{PTSC}}=0{ }^{\circ} \mathrm{C}\right)$ & $2.3 \pm 0.23$ & $4550 \pm 300$ & $6100 \pm 250$ & $6600 \pm 350$ & $3150 \pm 200$ & $6950 \pm 700$ & $3600 \pm 100$ \\
\hline $\operatorname{MIP}\left(T_{\mathrm{PTSC}}=50^{\circ} \mathrm{C}\right)$ & $1.9 \pm 0.19$ & $3850 \pm 250$ & $6650 \pm 250$ & $5900 \pm 350$ & $3700 \pm 200$ & $7000 \pm 700$ & $4600 \pm 150$ \\
\hline $\operatorname{ICP}\left(T_{\mathrm{PTSC}}=60^{\circ} \mathrm{C}\right)$ & $2.0 \pm 0.20$ & $6650 \pm 400$ & $6050 \pm 250$ & $4000 \pm 250$ & $5250 \pm 400$ & $8600 \pm 850$ & - \\
\hline
\end{tabular}

${ }^{a} T_{\mathrm{PTSC}}-\mathrm{PTSC}$ temperature. 

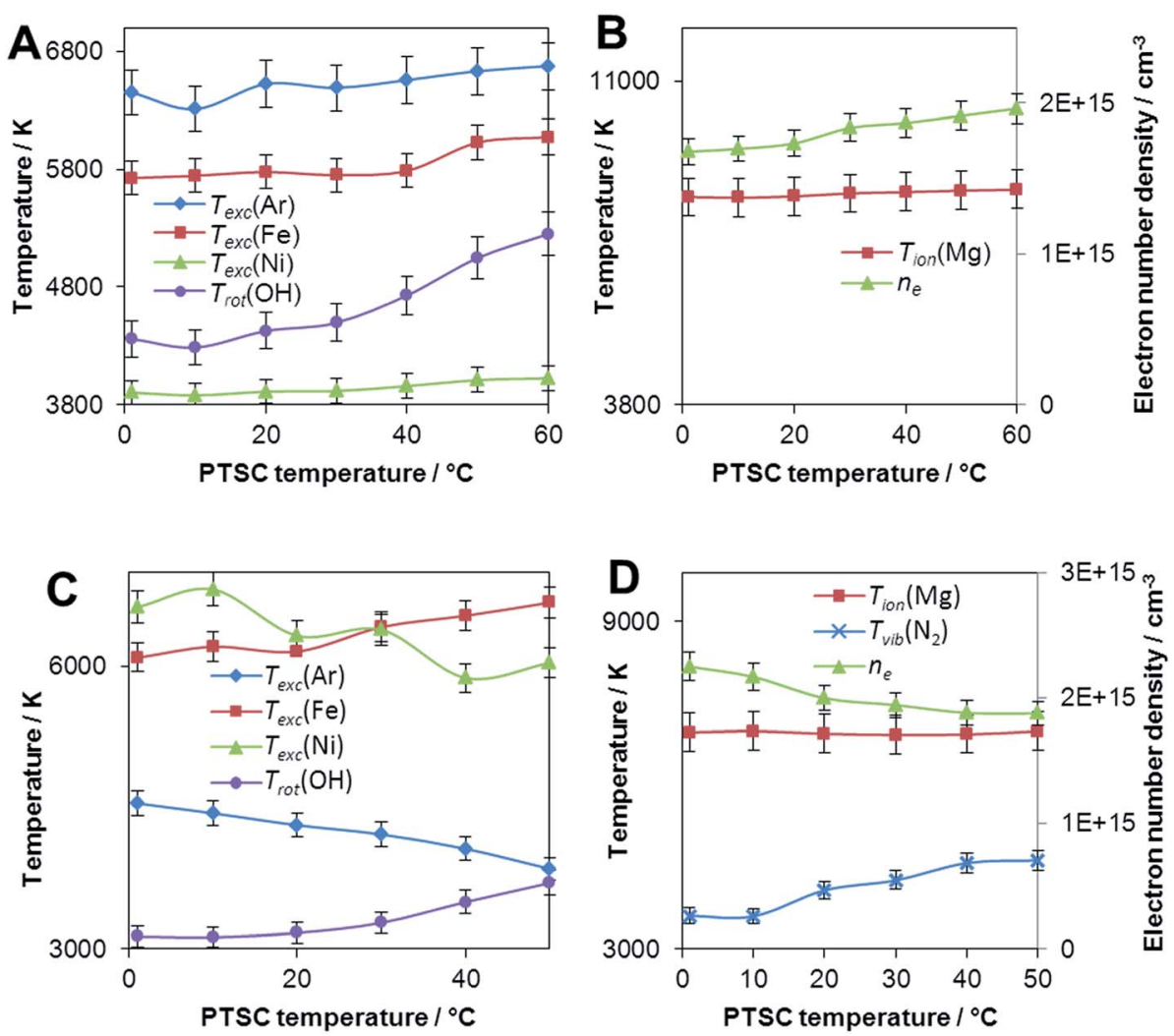

Fig. 4 Plasma parameters as a function of PTSC temperature under PCVG-PN-PTSC conditions. (A) $\left(T_{\text {exc }}(\mathrm{Ar}), T_{\text {exc }}(\mathrm{Fe}), T_{\text {exc }}(\mathrm{Ni}), T_{\text {rot }}(\mathrm{OH})\right)$ and $(\mathrm{B})$ $\left(T_{\text {ion }}(\mathrm{Mg}), n_{\mathrm{e}}\right)$ show results obtained for ICP while (C) ( $\left.T_{\text {exc }}(\mathrm{Ar}), T_{\text {exc }}(\mathrm{Fe}), T_{\text {exc }}(\mathrm{Ni}), T_{\text {rot }}(\mathrm{OH})\right)$ and $(\mathrm{D})\left(T_{\text {ion }}(\mathrm{Mg}), n_{\mathrm{e}}, T_{\text {vib }}\left(\mathrm{N}_{2}\right)\right)$ for $\mathrm{MIP}$.

of $T_{\text {exc }}(\mathrm{Fe}), T_{\mathrm{vib}}\left(\mathrm{N}_{2}\right)$ and $T_{\text {rot }}(\mathrm{OH})$ may suggest that under plasma conditions related to elevated PTSC temperature some energy is transferred from $\mathrm{Ar}$ atoms to other heavy particles present in the plasma. In particular, this is confirmed by $28 \%$ increase of $T_{\text {vib }}\left(\mathrm{N}_{2}\right)$ with increasing the PTSC temperature between $0{ }^{\circ} \mathrm{C}$ and $50{ }^{\circ} \mathrm{C}$. It is known that nitrogen vibration states can trap energy and play the role of an energy reservoir in the plasma, which is important for specific excitation pathways. ${ }^{36}$ Also, plasma stability may be affected since plasma sustenance depends on Ar energy. In turn, the observed extensive $T_{\text {rot }}(\mathrm{OH})$ increase is disadvantageous from the point of view of the source durability. Too high gas temperature may cause torch material etching since the distance between the MIP discharge and torch inner wall is relatively low. However, the most important effect here is the decrease of $n_{\mathrm{e}}$ indicating that plasma is being suppressed under the examined conditions. It is known that low-power MIP plasma can accept only a limited amount of water, even in the vapor form. Reducing the sample flow rate would likely allow for MIP measurement at PTSC temperature exceeding $50{ }^{\circ} \mathrm{C}$. It has been noted that increase of water transport efficiency with increasing PTSC temperature caused an even depressive effect on analyte signal intensity and LOD values (an opposite effect compared to ICP). ${ }^{8,9}$ The highest emission intensity for all analytes for MIP was reached at a PTSC temperature of $0{ }^{\circ} \mathrm{C}$. All these facts suggest that, despite the increase in some parameters, the MIP robustness worsens with increasing PTSC temperature.

\section{Conclusion}

The fundamental characteristics of axially viewed argon ICP and MIP combined with PCVG-PN-PTSC have been investigated to examine the plasma response on PTSC temperature setting. The electron density and rotational temperature were found to be the plasma parameters much sensitive and reacting for changes under the experimental conditions. In turn, the ionization temperature values did not change significantly under the examined experimental conditions for both plasmas. The final effect of PTSC temperature varies depending on the plasma type used. In the light of spectroscopic plasma parameters determined, it seems that the addition of water vapor to the argon plasma gas significantly improves excitation conditions for analytes in ICP most probably due to the favorable increase in excitation and rotational temperatures of the plasma. The observed variations in several plasma parameters depending on PTSC temperature seem to be a result of affecting plasma robustness rather than analyte transport efficiency.

The PTSC temperature setting presents a more distinct influence on MIP than ICP plasma parameters. The MIP was less resistant to both excessive water loading and influence of water vapor. For the plasma loaded with increasing amount of water aerosol and vapor, the $n_{\mathrm{e}}$ value was found to gradually decrease. The excitation temperatures for $\mathrm{Ar}, \mathrm{Fe}$ and $\mathrm{Ni}$ were observed to be dramatically dependent on experimental conditions. Also, the vibrational temperature for nitrogen 
molecules is also much higher in the presence of water vapor. In contrast to the ICP, increase of PTSC temperature worsens plasma robustness and plasma stability for Ar-MIP.

\section{References}

1 K. Jankowski, J. Anal. At. Spectrom., 1999, 14, 1419-1423.

2 G. L. Long and L. D. Perkins, Appl. Spectrosc., 1987, 41, 980985.

3 A. Montaser, et al., Inductively Coupled Plasma Mass Spectrometry, John Wiley, Washington, 1998.

4 E. Peredes, et al., J. Anal. At. Spectrom., 2009, 24, 903-910.

5 M. Grotti, et al., Spectrochim. Acta, Part B, 2004, 59, 10011006.

6 W. Schrön and U. Müller, Fresenius' J. Anal. Chem., 1997, 357, 22-26.

7 A. Leclercq, et al., Anal. Chim. Acta, 2015, 885, 57-91.

8 K. Jankowski, et al., Microchem. J., 2014, 113, 17-21.

9 J. Giersz and K. Jankowski, Microchem. J., 2016, 124, 1-8.

10 J. Giersz, et al., Talanta, 2017, 167, 279-285.

11 G. Zhu and R. F. Browner, J. Anal. At. Spectrom., 1988, 3, 781789.

12 S. Long and R. Browner, Spectrochim. Acta, Part B, 1988, 43, 1461-1471.

13 P. Pohl and A. C. Broekaert, Anal. Bioanal. Chem., 2010, 398, 537-545.

14 P. Jamróz, et al., J. Anal. At. Spectrom., 2012, 27, 1772-1779.

15 G. Grindlay, et al., Spectrochim. Acta, Part B, 2016, 115, 8-15.

16 G. Grindlay, et al., Spectrochim. Acta, Part B, 2008, 63, 234243.

17 L. Tormen, et al., Spectrochim. Acta, Part B, 2010, 65, 959-966.

18 M. Wełna and W. Żyrnicki, J. Anal. At. Spectrom., 2009, 24, 832-836.
19 J. Borkowska-Burnecka, et al., Int. J. Spectrosc., 2016, 7521050.

20 T. D. Hettipathirana, et al., Spectrochim. Acta, Part B, 1990, 45, 271-280.

21 M. Włodarczyk and W. Żyrnicki, Spectrochim. Acta, Part B, 2003, 58, 511-522.

22 K. Jankowski, et al., Spectrochim. Acta, Part B, 1999, 54, 515525.

23 H. R. Griem, Plasma spectroscopy, McGraw-Hill Inc., New York, 1964.

24 C. de Izarra, J. Phys. D: Appl. Phys., 2000, 33, 1697-1704.

$25 \mathrm{~J}$. M. Mermet, Inductively coupled plasma emission spectroscopy. Part II: applications and fundamentals, John Wiley, New York, 1987.

26 L. Bardos, et al., J. Appl. Phys., 2001, 90, 1703-1709.

27 A. Zaidel, Spectral lines tables, Science, Moscow, 1977.

28 I. Ishii and A. Montaser, Spectrochim. Acta, Part B, 1991, 46, 1197-1206.

29 C. Corliss and W. Bozeman, Experimental transition probabilities for spectral lines of seventy elements, MIR edition, Moscow, 1968.

30 Y. Yin, et al., TrAC, Trends Anal. Chem., 2011, 10, 1672-1684.

31 Y. Q. Tang and C. Trassy, Spectrochim. Acta, Part B, 1986, 41, 143-150.

32 J. A. M. van der Mullen, Phys. Rep., 1990, 191, 109-220.

33 X. Guo, et al., Appl. Organomet. Chem., 2004, 18, 205-211.

34 C. Zheng, et al., Anal. Chem., 2010, 82, 3086-3093.

35 M. Grotti, et al., J. Anal. At. Spectrom., 2006, 21, 963-969.

36 A. Fridman and L. A. Kennedy, Plasma Physics and Engineering, Taylor \& Francis, London, 2004. 